This is an Accepted Manuscript of an article published by Taylor \& Francis in 'Journal of Consumer Health on the Internet' on 2015-10-02, available online: https://www.tandfonline.com/10.1080/15398285.2015.1094302.

Journal of Consumer Health on the Internet, 19(3-4):233-240, 2015

Published with license by Taylor \& Francis

ISSN: $1539-8285$ print/1539-8293 online

Routledge

Taylor \& Francis Group

DOI: $10.1080 / 15398285.2015 .1094302$

\title{
Patient Information Aid: Promoting the Right to Know, Evaluate, and Share Consumer Health Information Found on the Internet
}

\author{
VERA GRANIKOV, REEM EL SHERIF, and PIERRE PLUYE \\ McGill University, Montreal, Canada
}

Promoting the use of online consumer bealth information is critical to achieving the democratic right to know and cannot be separated from facilitating the process of finding and understanding this information. In addition, being informed and being able to share information with a clinician are fundamental principles enabling patient engagement in health care and shared decision making. Online consumer bealth information may contribute to positive patient outcomes such as improved knowledge, and even better health, while in some situations it also leads to increased worry. This type of negative outcome represents a common experience. Our bealth is important and therefore anything that touches our bealth can increase anxiety. In our view, worrying is not a disorder; only occasionally it is an incapacitating cyberchondria. Since 2005, our research has been exploring bealth information outcomes from the consumers' viewpoint. We are particularly interested in information outcomes such as the types of information use and the types of subsequent health outcomes. Thus, we are currently engaged in a participatory systematic mixed studies review aimed to identify these types of outcomes, and develop a Patient Information Aid, an aid to empower consumers and patients to find, understand, assess, and use online consumer bealth information.

(C) Vera Granikov, Reem El Sherif, and Pierre Pluye

Received August 20, 2015; revised October 15, 2015; accepted October 16, 2015.

Address correspondence to Vera Granikov, Department of Family Medicine, McGill University, 5858, chemin de la Côte-des-Neiges, Montreal, Quebec H3S 1Z1, Canada. E-mail: vera.granikov@mail.mcgill.ca

Color versions of one or more of the figures in the article can be found online at www. tandfonline.com/wchi. 
KEYWORDS Engagement in bealth care, information use, Internet, online consumer bealth information, the right to know

\section{INTRODUCTION}

The purpose of this article is to share some of our work and thoughts related to the viewpoints of consumers of online health information. Looking for health information remains one of the most common reasons for searches on the Internet (Fox and Duggan 2013). This is matched with a growing volume of available information and various initiatives to engage the public more actively in their health care (Smith and Duman 2009). First, making health information freely available is a necessary requirement to achieve Article 19 of the Universal Declaration of Human Right promoting the right to know, that is, to "seek, receive and impart [communicate] information and ideas through any media" (UN General Assembly 2014, December 10, 1948, 217 A (III)). Second, being informed and being able to share information with a clinician are fundamental principles enabling patient engagement in health care and shared decision making (Legare et al. 2011). Finally, the improvement of patient health outcomes relies on successful patient engagement in health care, for which health literacy is essential (Koh et al. 2013).

Online consumer health information may contribute to patient outcomes such as improved knowledge, more active participation in health care, and better health. For example, one survey reports that $86 \%$ of patients who discussed online health information with clinicians reported that this was beneficial (Gauld and Williams 2009). However, little is known about the outcomes of the use of online health information in primary care, and there is no comprehensive tool for assessing them. In addition, existing aids assist patients in making specific decisions, for example, online symptoms checkers, but there are none for helping patients find and use relevant general health information, for example, with their clinicians (a common patients' need). Since 2001, our research team at the Department of Family Medicine at McGill University has been studying the outcomes associated with the delivery and retrieval of clinical information from the viewpoint of clinicians such as nurses, pharmacists, and physicians (Pluye and Grad 2012; Information Technology Primary Care Research Group 2014). Since 2005, we have been exploring these outcomes from the consumers' viewpoint. We are particularly interested in the types of information use and the types of subsequent health outcomes. To identify these information outcomes, we are currently engaged in a participatory systematic mixed studies review funded by the Canadian Institutes of Health Research (CIHR is a public agency) (Granikov et al. 2014; Pluye, Grad et al. 2014; Pluye and Hong 2014). We will integrate the findings of this review into a Patient Information Aid; thus, empowering consumers and patients to find, understand, assess, and use online consumer health information. 


\section{THE INFORMATION ASSESSMENT METHOD FOR PATIENTS AND CONSUMERS (IAM4ALL)}

We started by developing and validating a questionnaire, the Information Assessment Method for patients and consumers (IAM4all), which can be used by the general public to assess outcomes associated with seeking and receiving online consumer health information (Pluye et al. 2014). We worked together with representatives of information consumers, consumer health information providers, literacy experts, information specialists, and researchers. This method stimulates reflection on health information while documenting the value of information. The IAM4all is based on information studies and a theoretical model, called the 'Acquisition Cognition Application - Level of Outcomes' model (ACA-LO) (Saracevic and Kantor 1997; Pluye et al. 2013). This model explains how information is valuable from the end user's point of view in terms of its situational relevance, its cognitive impact, its use, and its subsequent health benefits.

\section{WHAT THE CONSUMERS HAD TO SAY ABOUT USING ONLINE CONSUMER HEALTH INFORMATION}

Consumers' experience with online health information is not all positive; as one consumer called it a "double-edged sword." In this article, we highlight our findings from interviewing 16 consumers. All were fluent in English or French and had no training or experience in health sciences or information studies. According to the Short Test of Functional Health Literacy in Adults (S-TOFHLA), their level of health literacy was "adequate" (Nurss et al. 2001). First, participants were asked to describe their general experience with online consumer health information. Second, they read a public health leaflet and completed an early version of the IAM4all questionnaire based on the information in the leaflet. In terms of their general experience with online consumer health information, interviewees openly reported that having more information can increase worry, while it may be worth it, and expressed difficulties to share information with clinicians.

Six interviewees talked of increased anxiety and two suggested that information could be harmful. For example, one interviewee associated the "dangers" with looking up symptoms: "You put in how you feel and it will tell you have cancer, you have gout, [... ] You've got every single disease in the world." This consumer confirmed the potential negative outcomes of looking up symptoms by saying: "Even if these are exactly the symptoms that you have, but you are not a doctor. It can be belpful, but also damaging." Another one of our participants shared this idea by saying: "I tend to over-worry, I tend not to look up for too much information [...]. The more information I have the more I will worry." The comments on this type of 
negative outcome of online consumer health information represent a common experience (increased worry). Our health is important; we have the right to know and to be engaged in our care. Thus, anything that touches our health can increase worry, but worrying is not a disorder. In other words, normal online health information-seeking-related worry cannot be described as a pathological incapacitating case of cyberchondria (Loos 2013; Starcevic and Berle 2013; Norr et al. 2014).

Nine of the interviewees reported an overall positive experience looking for health information online. Three interviewees said that more, even when too much, information is better. For example, this consumer, while recognizing that consumers need to be aware and educated enough to be able to read the information properly, claims, "Maybe it's too much information, but I'd rather know more." As stated by another: "Personally, I just want to know; I don't want to sit in a waiting room for four bours for something that could have a simple answer; I want answers before I go anywhere or do anything."

Finally, seven interviewees expressed some level of difficulty using the information found on the Internet in discussion with a clinician. One described the situation like this: "[...] depends on the doctor, a lot of doctors don't like their patient to come up with information, it is their domain." Another interviewee shared a similar opinion: "You have to be quite careful at saying 'I have been reading on the internet, and this could be that' he is not very open to bis patients playing doctor." These shared experiences of reluctance to discuss online health information with clinicians are commonly reported in the literature. The reasons may be patients feeling embarrassed and unsure how to explain the information, or concern that the physician does not want to hear about their use of the Internet for health information (Silver 2015). Moreover, some studies reported that the patient-physician relationship worsened after patients shared the health information found online with their physicians, while others demonstrated decreased trust and lower compliance to the management plan (Kivits 2006; Peña-Purcell 2008; Kim and Kim 2009). Clinicians' attitudes represent a barrier to understanding, assessing, and using online consumer health information. How can patients be more involved in their care when they hesitate to use (share) the information they find in clinical encounters?

\section{A NEW TOOL TO FACILITATE THE USE OF ONLINE CONSUMER HEALTH INFORMATION}

Passing on information seems to be a one-way knowledge translation (from clinicians to patients). Our work leads us to propose the development of the Patient Information Aid, which may facilitate a two-way knowledge translation (from patients to clinicians and from clinicians to patients). The Patient Information Aid is an aid to facilitate the use of online consumer health 
information, potentially leading to better health outcomes. The aid would have two main functions. The first function would direct consumers who have trouble finding information to consumer health information specialists, and those who have challenges understanding the found information to

Patient seeks consumer health information on their mobile device, which launches the app

If information is found, the app proposes links to high quality resources and $\mathbf{a}$ button to access evaluation questions

Q1: Did you find the information you were looking for?

(situational relevance)

If 'No', FIND HEALTH LIBRARIAN will provide links to consumer health information services (e.g. in hospitals where patients are registered)

If 'Yes', Q2: What do you think about this information?

(cognitive impact)

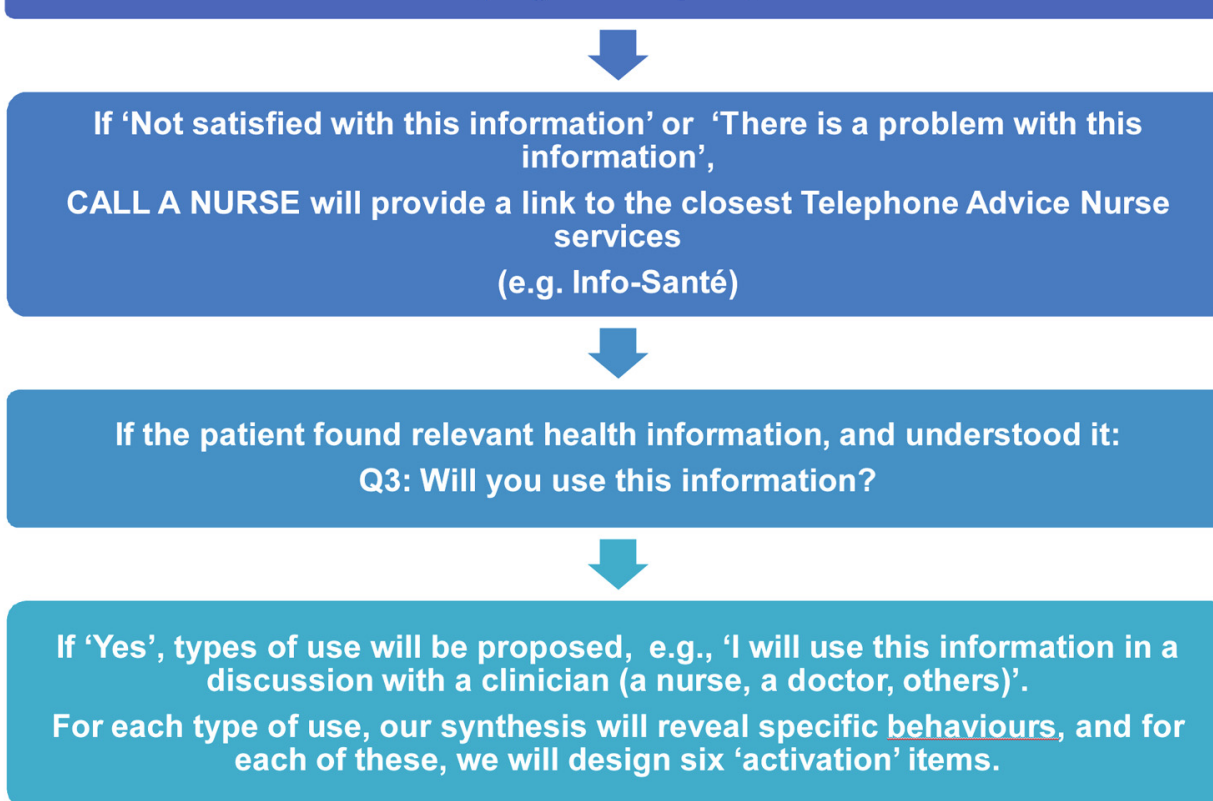

FIGURE 1 Starting model for designing the Patient Information Aid (based on IAM4all). 
public health nurses (Figure 1). Information specialists are experts trained in finding information adapted to one's level of health literacy, and can direct consumers to reliable and accessible information resources and workshops. Moreover, directing consumers to useful and reliable information, as well as helping them process and understand it, has the potential to overcome health literacy barriers, and decrease worries (Starcevic and Berle 2013). In line with recommendations of the Health Literate Care Model, the aid will be facilitating contact with health literacy community resources (Koh et al. 2013). Second, the aid will facilitate information use with activation items (Godin 2012), which will help consumers act on the information they find. Patients find it difficult to communicate with clinicians, and these activation items could be the solution (Diaz et al. 2002; Kivits 2006).

In conclusion, we believe that our body of work, and specifically the Patient Information Aid, is a step toward achieving the right to know, improving health information literacy, and promoting consumers' and patients' engagement in their health care by facilitating the process of finding, understanding, evaluating, and using health information.

\section{ACKNOWLEDGEMENTS}

The authors thank Gillian Bartlett, Roland M. Grad, David L. Tang, Janique Johnson-Lafleur, Michael Shulha, Maria Cristiane Barbosa Galvão, Ivan L. M. Ricarte, Randolph Stephenson, Linda Shohet, Jo-Anne Hutsul, Carol A. Repchinsky, Ellen Rosenberg, Bernard Burnand, France Légaré, Lynn Dunikowski, Susan Murray, Jill Boruff, Francesca Frati, Lorie Kloda, Ann Macaulay, François Lagarde, and Geneviève Doray for their ongoing collaboration and support with the development of the Information Assessment Method of Patients and Consumers.

\section{REFERENCES}

Diaz, J. A., R. A. Griffith, J. J. Ng, S. E. Reinert, P. D. Friedmann, and A. W. Moulton. 2002. Patients' use of the Internet for medical information. Journal of General Internal Medicine 17, no. 3: 180-85. doi:10.1046/j.1525-1497.2002.10603.x

Fox, S., and M. Duggan. 2013. Health Online. Pew Internet 2013. http://pewinternet. org/ /media//Files/Reports/PIP_HealthOnline.pdf (accessed August 23, 2013).

Gauld, R., and S. Williams. 2009. Use of the Internet for health information: A study of Australians and New Zealanders. Informatics for Health and Social Care 34, no. 3: 149-58. doi:10.1080/17538150903102448

Godin, G. 2012 Les comportements dans le domaine de la santé: Comprendre pour mieux intervener. Montréal: Presses de l'Université de Montréal.

Granikov, V., P. Pluye, C. A. Repchinsky, L. Dunikowski, F. Frati, L. Shohet, L. Vineberg, G. Bartlett, B. Burnand, S. Desroches, C. M. B. Galvão, R. Grad, F. Légaré, F. Millerand, J.-A. Hutsul, L. Kloda, B. Rihoux, M. Shulha, D. L. Tang, 
and R. El Sherif. 2014. Uncovering the outcomes of the use of online consumer health information: A participatory systematic mixed studies review. Poster presented at the Canadian Health Libraries Association Conference, Montreal, Quebec, June 16-20.

Information Technology Primary Care Research Group. 2014. The information assessment method. Department of Family Medicine, McGill University. http:// www.mcgill.ca/iam (accessed May 1, 2014).

Kim, J., and S. Kim. 2009. Physicians' perception of the effects of Internet health information on the doctor-patient relationship. Informatics for Health \& Social Care 34, no. 3: 136-48. doi:10.1080/17538150903102422.

Kivits, J. 2006. Informed patients and the Internet: A mediated context for consultations with health professionals. Journal of Health Psychology 11, no. 2: 269-82. doi:10.1177/1359105306061186

Koh, H. K., C. Brach, L. M. Harris, and M. L. Parchman. 2013. A proposed 'health literate care model' would constitute a systems approach to improving patients' engagement in care. Health Affairs 32, no. 2: 357-67. doi:10.1377/hlthaff. 2012.1205

Legare, F., D. Stacey, S. Gagnon, S. Dunn, P. Pluye, D. Frosch, J. Kryworuchko, G. Elwyn, M.-P. Gagnon, and I. D. Graham. 2011. Validating a conceptual model for an inter-professional approach to shared decision making: A mixed methods study. Journal of Evaluation in Clinical Practice 17, no. 4: 554-64. doi:10.1111/ j.1365-2753.2010.01515.x

Loos, A. 2013. Cyberchondria: Too much information for the health anxious patient? Journal of Consumer Health on the Internet 17, no. 4: 439-45. doi:10.1080/ 15398285.2013.833452

Norr, A. M., B. J. Albanese, M. E. Oglesby, N. P. Allan, and N. B. Schmidt. 2014. Anxiety sensitivity and intolerance of uncertainty as potential risk factors for cyberchondria. Journal of Affective Disorders 174: 64-69. doi:10.1016/j.jad.2014. 11.023

Nurss, J., R. Parker, M. Williams, and D. Baker. 2001. Directions for administration and scoring and technical data, short test of functional health literacy in adults (S-TOFHLA-English \& S-TOFHLA-Spanish). Snow Camp, NC: Peppercorn Books \& Press.

Peña-Purcell, N. 2008. Hispanics' use of Internet health information: An exploratory study. Journal of Medical Library Association 96, no. 2: 101-07. doi:10.3163/ 1536-5050.96.2.101

Pluye, P., R. Grad, C. Repchinsky, L. Dunikowski, F. Frati, L. Shohet, L. Vineberg, G. Bartlett, B. Burnand, S. Desroches, C. Galvao, F. Legare, F. Millerand, J.-A. Hutsul, L. Kloda, B. Rihoux, M. Shuhla, D. Tang, R. El Sherif, and V. Granikov. 2014. In primary health care, what are the outcomes associated with the use of online consumer health information? A participatory systematic mixed studies review (protocol registration). PROSPERO 2014:CRD42014009738. http://www. crd.york.ac.uk/PROSPERO/display_record.asp?ID=CRD 42014009738 (accessed November 4, 2014).

Pluye, P., R. Grad, C. Repchinsky, B. Jovaisas, J. Johnson-Lafleur, M.-E. Carrier, V. Granikov, B. Farrell, C. Rodriguez, G. Bartlett, C. Loiselle, and F. Légaré. 2013. Four levels of outcomes of information-seeking: A mixed methods study in 
primary health care. Journal of the American Society for Information Science and Technology 64, no. 1: 108-25. doi:10.1002/asi.22793

Pluye, P., and R. M. Grad. 2012. Assessing and improving clinical information. International Innovation Report 17: 51-53. http://www.internationalinnovation-healthcare.com/magazines/HC17/index.html.

Pluye, P., V. Granikov, G. Bartlett, R. M. Grad, D. L. Tang, J. Johnson-Lafleur, M. Shulha, C. M. B. Galvão, I. L. M. Ricarte, R. Stephenson, L. Shohet, J.-A. Hutsul, C. A. Repchinsky, E. Rosenberg, B. Burnand, F. Légaré, L. Dunikowski, S. Murray, J. Boruff, F. Frati, L. Kloda, A. Macaulay, F. Lagarde, and G. Doray. 2014. Development and content validation of the information assessment method for patients and consumers. Journal of Medical Internet Research, Research Protocols 3, no. 1: e7. doi:10.2196/resprot.2908

Pluye, P., and Q. N. Hong. 2014. Combining the power of stories and the power of numbers: Mixed methods research and mixed studies reviews. Annual Review of Public Health 35, no. 1: 29-45. doi:10.1146/annurev-publhealth-032013182440

Saracevic, T., and P. B. Kantor. 1997. Studying the value of library and information services. Part I. Establishing a theoretical framework. Journal of the American Society for Information Science and Technology 48, no. 6: 527-42. doi:10.1002/(SICI)1097-4571(199706)48:6<527::AID-ASI6 > 3.0. CO;2-W

Silver, M. P. 2015. Patient perspectives on online health information and communication with doctors: A qualitative study of patients 50 years old and over. Journal of Medical Internet Research 17, no. 1: e19. doi:10.2196/jmir.3588

Smith, S., and M. Duman. 2009. The state of consumer health information: An overview. Health Information E Libraries Journal 26, no. 4: 260-78. doi:10.1111/ j.1471-1842.2009.00870.x

Starcevic, V., and D. Berle. 2013. Cyberchondria: Towards a better understanding of excessive health-related Internet use. Expert Review of Neurotherapeutics 13, no. 2: 205-13. doi:10.1586/ern.12.162

UN General Assembly. 2014. Universal Declaration of Human Rights 10 December 1948, 217 A (III). http://www.refworld.org/docid/3ae6b3712c.html. (accessed May 1, 2014).

\section{ABOUT THE AUTHORS}

Vera Granikov (vera.granikov@mail.mcgill.ca), Reem El Sherif (reem.elsherif@ mail.mcgill.ca), and Pierre Pluye (pierre.pluye@mcgill.ca) are all affiliated with the Department of Family Medicine, McGill University, Montreal, Quebec, Canada. Vera Granikov, MLIS, is a research-embedded health information specialist. Reem El Sherif, MD, is a Master of Science candidate. Pierre Pluye, $\mathrm{MD}, \mathrm{PhD}$, is a full professor and the Director of Methodological Developments, Quebec Support Unit. 